\title{
Unresectable Synovial Sarcoma
}

National Cancer Institute

\section{Source}

National Cancer Institute. Unresectable Synovial Sarcoma. NCI Thesaurus. Code C153074.

Synovial sarcoma that is not amenable to surgical resection. 